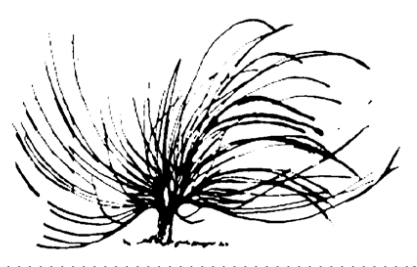

\title{
Da escuta ao registro: estilos de discurso reportado em relatórios de estágio ${ }^{1}$
}

\author{
Thomas Massao Fairchild ${ }^{2}$ \\ Universidade Federal do Pará \\ Brasil \\ tmfairch@yahoo.com.br
}

\begin{abstract}
Resumo
Analisamos a construção do "discurso reportado" em relatórios de estágio de estudantes de Letras de uma universidade pública brasileira com o objetivo de estabelecer relações entre o estilo empregado para o registro de enunciados de terceiros e os posicionamentos assumidos pelo autor. Acreditamos que a maneira como os estagiários registram esses enunciados fornece indícios de como eles escutam a aula e de como trabalham na retomada e organização de sua experiência. A análise dos estilos de discurso reportado pode evidenciar algumas formas de percepção da escola disponíveis na cultura universitária e, de igual modo, as escolhas individuais do estagiário frente a essa cultura quando da construção de seu texto. Analisamos os dados a partir de Bakhtin (2004, 2015), recorrendo aos conceitos de estilo "linear" e "pictórico", ao contraponto entre "análise da expressão" e "análise do conteúdo" e à noção de "discurso bivocal". Encontramos passagens representativas de estilos variados, mas de modo geral não encontramos sinais de um trabalho por meio do qual o estilo seja mobilizado em favor da construção de um posicionamento coeso e persistente. O registro dos enunciados de professores e
\end{abstract}

\section{(1) $\odot$}

http://dx.doi.org/10.15359/rep.esp-20-1.3

1 O presente trabalho foi realizado com apoio do CNPq, Conselho Nacional de Desenvolvimento Científico e Tecnológico - Brasil (Processo no 458449/2014-8)

2 Professor Adjunto da Universidade Federal do Pará, Doutor em Educação pela Universidade de São Paulo. 
alunos parece ser influenciado por questões que incluem desde problemas de redação até a postura do estagiário diante do próprio enunciado que está sendo citado.

Palavras-chave: Formação de professores, estágio, escrita, discurso reportado.

\begin{abstract}
We analyze cases of reported speech in internship reports written by Brazilian Language Arts students with the aim to associate the style employed by them when citing a third party's speech with the positions they sustain in their texts. We believe that the way in which students report this speech hints at how they "listen" to what goes on in class and how they revisit and organize their own experience by writing about it. That kind of analysis can cast light upon the forms of perception of the school available in academic culture and, all the same, the individual choices made by students when faced with that culture. To analyze our data, we draw from M. Bakhtin (2004, 2015), especially the notions of "linear" and "pictoric" style, the counterpoint between "expression analysis" and "content analysis" and the concept of "bivocal discourse". We were able to find passages that represent various styles of reported speech but we could hardly find any signs of a particular style being employed to support the construction of a cogent and persistent position. It would seem that reporting teachers' and students' speech is influenced by questions that range from phrasing problems to how the author of the report reacts to the speech that is being reported.
\end{abstract}

Keywords: teacher education, internship, writing, reported speech

\title{
1. Introdução
}

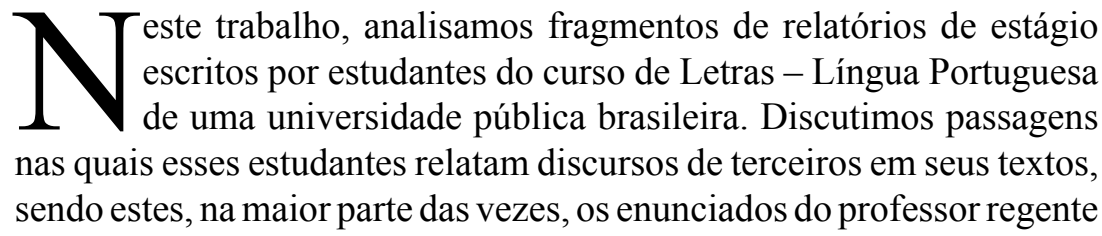


ou dos alunos da turma. Partimos do pressuposto de que a produção de relatos detalhados e reflexivos a respeito das práticas consiste, ao mesmo tempo, em um trabalho formativo essencial para o estudante universitário e em uma fonte de informações para o formador, que por meio deles pode avaliar esse estudante e ajustar as ações pedagógicas do processo formativo em curso.

Nossas análises, e toda a discussão sobre formação docente que extraímos delas, se baseiam numa perspectiva discursiva da linguagem. Neste trabalho, devido ao recorte analítico (o "discurso reportado"), referimo-nos sobretudo às reflexões de $\mathrm{M}$. Bakhtin, e, eventualmente, a autores que se baseiam nele ou cuja perspectiva nos parece análoga em algum aspecto. Antes de passarmos a essas análises, detalhamos a maneira como, dentro dessa perspectiva teórica, percebemos as implicações mútuas entre o trabalho de escrita e a formação docente. Esquematizamos essa apresentação em quatro pontos enumerados abaixo.

A. Uma aula consiste, para nós, em um acontecimento discursivo3. Materialmente, uma aula é um conjunto de enunciados e pode ser analisada como tal; os enunciados da aula não são "parte" da aula, não "complementam" nem se "articulam" com "outras dimensões" da aula (como materiais didáticos, gestos profissionais, tarefas ou quaisquer elementos considerados extra-discursivos) - a materialidade da aula é o próprio discurso que a constitui. Escrever sobre uma aula, nessa perspectiva, não é uma atividade que esteja em um plano distinto do próprio ato de ministrar a aula - a escrita não está para a aula como o "discurso" está para a "ação". Escrevendo, produzem-se enunciados de natureza fundamentalmente idêntica aos enunciados produzidos quando se está lecionando em classe e, nesse sentido, escrever é dar seguimento ao discurso em que a própria aula consiste. É, ao mesmo tempo, produzir enunciados que respondem aos enunciados originalmente pronunciados no espaço da sala, numa atividade que sustenta o pensamento sobre o ensino e produz novas possibilidades de tomada de posição sobre ele, bem como inaugura possibilidades de ação didática futura. O diálogo essencial da relação pedagógica - o engajamento com o aluno, a avaliação de seu desempenho, a escuta de suas dúvidas e impulsos,

3 Ao dizer isso, inserimo-nos em uma longa tradição de pensamento sobre a Educação existente no Brasil, na qual a aula não é tomada do ponto de vista didático, enquanto "acontecimento particular" de uma esfera própria (a escola), mas encarada como discurso socialmente produzido. Para uma visão sintética dessa perspectiva, consulte-se Geraldi (2010). 
mas também a leitura constante daquilo que se ensina, a apropriação e o tensionamento dos saberes escolares - esse diálogo não se encerra quando bate o sinal; ele se prolonga, com igual ou maior vivacidade, na atividade intelectual subsequente.

B. A escrita fornece um suporte para essa atividade intelectual do professor sobre sua própria experiência ${ }^{4}$. Isso acontece na medida em que, relatando o que viu e ouviu na sala de aula, bem como o que disse e fez ouvir, o professor produz (para si mesmo, em primeiro lugar, e para outros) um recorte relativamente objetivável do processo dialógico em que esteve (e ainda está) constituído como "ator". Grosso modo, escrevendo o que se passou em sala, seja "externamente" (narrando acontecimentos palpáveis e reportando falas literais), seja "internamente" (descrevendo pensamentos e sensações ou procurando dar destaque a entonações e outros aspectos menos explícitos), o professor pode retornar à aula e reviver, em diferentes condições, as "cenas" de que tomou parte. A existência material de um relato escrito, ainda que apenas em esboço, aumenta as chances de o sujeito se confrontar com aspectos da aula que, de outra forma, desapareceriam no desenrolar de uma rotina de trabalho - razão pela qual defendemos que a produção de um relatório não deve jamais ser substituída por outras formas de "avaliação prática". Na melhor das hipóteses, a produção de um relato detalhado pode fornecer dados para o desenvolvimento de reflexões analíticas que aumentam a capacidade de compreensão e de tomada de posição do professor frente ao ensino (inclusive o seu próprio ensino).

C. A produção de um bom relato da aula está diretamente ligada ao desenvolvimento de uma habilidade de escuta. Com isso estamos dizendo, antes de tudo, que um relatório de estágio não nos interessa para avaliar a qualidade da escrita de um estudante (embora possa ser usado para esse fim); a pergunta fundamental não é "quais são as características de um bom relatório?", mas sim "o que se deve esperar que o estudante perceba da aula?". Um aspecto essencial do relato consiste no modo como o estagiário registra em seu texto os enunciados produzidos ali, e a qualidade desse registro depende em primeiro lugar (embora não apenas) do modo como esse estagiário "escuta" a si mesmo e aos que falam à sua volta. Uma boa escuta não consiste unicamente na capacidade

4 Neste ponto estamos levando em consideração o conceito de "trabalho de escrita" formulado por Riolfi (2011). 
de reproduzir com fidelidade as palavras dos outros, e às vezes nem sequer coincide com isso (embora aprender a relatar o que alguém disse sem distorcer ou omitir suas palavras seja um bom começo). Acima de tudo, uma boa escuta consiste em perceber as relações "dialógicas" que se estabelecem entre os enunciados - onde há uma fala séria e onde está uma ironia ou um comentário desdenhoso; onde o tom de voz transforma um pedido numa ameaça, uma ordem em um ato de encorajamento, e assim por diante. Essas relações se dão entre os enunciados produzidos dentro da sala de aula (nas trocas entre o professor e o aluno, na forma de se ler em voz alta um livro didático etc.), mas também entre estes e outros enunciados "externos" à sala (a legislação sobre o ensino em todas as suas formas, as expectativas sociais sobre a escola, a própria universidade representada pelo estagiário etc.).

D. A produção de um bom relato também está diretamente ligada ao desenvolvimento de um estilo de escrita. Além da capacidade de escuta de que acabamos de falar, o estagiário também precisa se haver com todos os problemas relativos aos modos de expressar devidamente, em forma escrita, o que "escutou" durante a aula. Pode-se perceber algo muito sério - mas como dizê-lo? O que será de bom tom e o que soará excessivamente severo, ou desnecessariamente crítico? Certos episódios quase falam por si: é relativamente simples registrar, de forma colorida, cenas de embate, provocações e conflitos que não são raros no cotidiano escolar. Para além disso, no entanto, a expressão das trocas cotidianas da sala de aula demanda um grande esforço estilístico. Se a representação escrita dos estilos de fala de uma época é uma questão dificilmente resolvida por autores literários (conforme vemos na discussão original de Bakhtin), o que seria um grau de exigência justo para um professor em formação? Neste ponto, sem dúvida temos mais perguntas do que respostas, e é por essa razão que nos propomos a observar os usos do "discurso reportado" em relatórios de estudantes de Letras. Imaginamos poder encontrar aí indícios de como percebem a experiência da aula e a organizam em texto, tornando-a compartilhável com outros. Esperamos também começar a descrever ao menos alguns traços da cultura escolar dentro da qual esses relatórios são produzidos, de modo a colocar em discussão os resultados alcançados pelos estudantes não apenas enquanto desempenho individual, mas também enquanto evidência dos parâmetros que vêm sendo adotados pelas instituições nas quais essa escrita é promovida. 
Trabalhamos sobre uma amostra de 34 relatórios produzidos nos anos de 2014 e 2015 por estudantes de uma disciplina que prevê a realização de estágio no Ensino Fundamental. Esses alunos cumpriram 50 horas de estágio em um semestre, sendo 30 horas de observação e 20 horas de regência; também lhes foi exigido que entregassem, junto com o relatório, um ensaio de cerca de 10 páginas contendo a discussão de um problema de pesquisa específico, elaborado por eles ao longo do semestre 5 . Como se trata de nossos próprios alunos, é preciso dizer que durante a disciplina eles tiveram contato com as concepções que expusemos anteriormente e foram submetidos a exigências que condizem com elas, especialmente com relação à necessidade de fazer registros sistemáticos e precisos das aulas que presenciaram. Isso significa que nossos dados provém de uma pesquisa-ação e os resultados apresentados aqui não são facilmente generalizáveis. Possivelmente encontramos nesse corpus ocorrências mais numerosas e amplas dos casos que nos interessam (enunciados de terceiros citados por meio do discurso reportado) do que se tomássemos outra amostra. Em todo caso, a questão que levantamos - como os estagiários resolvem a tarefa de incluir esses enunciados em seu próprio discurso - é posterior à produção dos relatórios e nunca foi explicitamente colocada para esses alunos.

Para analisar os dados, recuperamos algumas reflexões acerca do discurso reportado que encontramos em dois pontos da obra de Bakhtin - a terceira parte de Marxismo e Filosofia da Linguagem (2004) e Problemas da Poética de Dostoievski (2015). Na primeira, o autor apresenta uma série de categorias com as quais problematiza os "acentos" estilísticos no discurso reportado ${ }^{6}$, referindo-se quase sempre à literatura - não vamos nos ater sistematicamente a cada ponto de sua argumentação, mas nos valeremos de algumas passagens pontuais para analisar exemplos do nosso corpus. Com relação à segunda obra, recorremos especialmente ao conceito de "discurso bivocal" e às implicações da noção de "polifonia" desenvolvida ali para a análise do discurso reportado.

5 Não consideramos importante distinguir quando citamos um excerto do relatório propriamente dito e quando citamos um excerto do ensaio, já que, a despeito da diferença no plano textual, as passagens de nosso interesse tendem a ser semelhantes do ponto de vista de sua constituição enunciativo-discursiva.

6 "Estilo linear" vs. "estilo pictórico"; "vertente analisadora do conteúdo" vs. "vertente analisadora da expressão"; depois, "discurso direto preparado", "discurso direto esvaziado", "discurso citado antecipado e disseminado" etc. 


\section{A separação do discurso citado: o linear e o pictórico}

Bakhtin (2004) distingue dois grandes "estilos" ou "orientações" do discurso citado - o estilo linear e o estilo pictórico. Em sua perspectiva, essas tendências dizem respeito aos modos como, em seu encadeamento histórico, o discurso elabora e disponibiliza ao próprio pensamento formas específicas de perceber o real - incluindo-se formas de se escutar e dar a palavra ao outro. A emergência de um estilo de discurso, nesse sentido, revelaria mais sobre os processos ideológicos envolvidos em determinada prática social do que sobre escolhas ou características individuais do autor de um texto, como fica claro nos comentários abaixo ${ }^{7}$ :

(...) quando sabemos lê-lo, [o discurso citado] dá-nos indicações, não sobre os processos subjetivo-psicológicos passageiros e fortuitos que se passam na 'alma' do receptor, mas sobre as tendências sociais estáveis características da apreensão ativa do discurso de outrem que se manifestam nas formas da língua. (...) Estamos bem longe, é claro, de afirmar que as formas sintáticas - por exemplo as do discurso direto ou indireto - exprimem de maneira direta e imediata as tendências e as formas da apreensão ativa e apreciativa da enunciação de outrem. (...) Mas esses esquemas e suas variantes só podem ter surgido e tomado forma de acordo com as tendências dominantes da apreensão do discurso de outrem; além disso, na medida em que esses esquemas assumiram uma forma e uma função na língua, eles exercem uma influência reguladora, estimulante ou inibidora, sobre o desenvolvimento das tendências da apreensão apreciativa (...). (Bakhtin, 2004, pp. 146-147)

Quando fazemos o aporte dessas considerações para a análise do "discurso reportado" em relatórios de estágio, nos vemos levados a indagar quais seriam as "tendências dominantes de apreensão do discurso de outrem" no seio das práticas que envolvem a escrita sobre o ensino em nossos dias - isto é, quais são as formas e os estilos disponíveis, nos discursos da pesquisa em educação atuais, para se ouvir e

7 Esse ponto de vista é explicitado de outra forma no texto Os gêneros do discurso (2010), em que Bakhtin diferencia claramente o estilo individual dos estilos de gênero. 
se dar a palavra a professores e alunos. Uma questão derivada dessa é como cada estagiário se posiciona individualmente frente a essas "tendências" na produção de seu texto - seja quando adere às "tendências dominantes", seja quando trabalha para diferenciar-se de um tom médio e individualizar sua posição enquanto "autor" do texto.

A. O primeiro estilo de discurso citado descrito por Bakhtin é chamado por ele de "linear". Ele seria caracterizado por uma forma específica de reação à palavra do outro, "[visando] à conservação da sua integridade e autenticidade" (Bakhtin, 2004, p. 148). E ainda: "A tendência principal do estilo linear é criar contornos exteriores nítidos à volta do discurso citado, correspondendo a uma fraqueza do fator individual interno" (Bakhtin, 2004, p. 150). Trata-se de uma situação em que há um menor grau de análise das palavras citadas e uma menor intensidade das avaliações ou comentários que o discurso narrativo pode realizar em relação ao discurso reportado ${ }^{8}$.

Encontramos relatórios escritos em "estilo linear", nos quais predomina a transcrição de falas ou a reprodução de enunciados como anotações da lousa, passagens do material didático, respostas extraídas de cadernos de alunos etc. Por vezes o discurso narrativo propriamente dito se reduz às frases que anunciam o discurso citado e, em algumas passagens, é quase inteiramente substituído por ele. O trecho a seguir dá-nos um exemplo.

\section{EXCERTO 1}

A professora começa a escrever no quadro, vira para os alunos e diz:

PROF.: - Eu vou colocar aqui no quadro algumas frases e vocês vão grifar os adjetivos.

ALUNO 6: - É para deixar quantas linhas?

PROF.: - Só uma.

A professora continua escrevendo no quadro.

8 No capítulo 10 da mesma obra, falando sobre o discurso indireto, Bakhtin propõe uma dicotomia que nos parece muito semelhante, entre o que chama de "vertente analisadora do conteúdo" e "vertente analisadora da expressão". Para simplificar, vamos falar aqui apenas de "estilo linear" e "estilo pictórico", referindo-nos tanto ao discurso direto quanto ao discurso indireto (isto é, ao "discurso reportado" de modo geral). 


\section{PROF.: - Vocês vão identificar e grifar os adjetivos.}

Os alunos copiam a atividade.

Neste excerto, a interferência do discurso narrativo sobre o discurso citado é mínima e praticamente se reduz à nomeação dos locutores no início de cada fala. $\mathrm{O}$ uso de caixa alta para designar os locutores (PROF, ALUNO 6), além de alguns recursos de pontuação (dois pontos, aspas, travessão), contribuem para separar ao máximo os enunciados citados tanto um do outro quanto em relação ao discurso narrativo. Este último consiste em algumas frases de pouco teor informativo, até mesmo dispensáveis ("a professora continua escrevendo" etc.), ou se transforma em marcação visual: podemos imaginar uma leitura em voz alta na qual apenas o conteúdo das falas citadas fosse pronunciado e o "narrador" se tornaria efetivamente mudo.

Os efeitos de escolhas estilísticas numa avaliação do relatório, enquanto documento do processo formativo de um estudante, são complexos. Parece-nos plausível dizer que o uso do estilo "linear", no excerto 1, não leva necessariamente a um ganho em termos de objetividade do registro da aula. O relato "preciso" da troca verbal entre professor poderia ser resumido em uma única frase em discurso indireto (" a professora disse aos alunos que eles deveriam identificar e grifar os adjetivos no quadro") sem que se perdesse qualquer informação relevante para uma reflexão sobre a própria aula relatada. Parece então que, nesse caso, embora se reconheça um esforço do estagiário no sentido de produzir um relato acurado, ele falha na seleção do que registrar. Atendo-se a um estilo semelhante, outros estagiários conseguem obter informações pertinentes sobre a aula por selecionarem melhor o objeto de suas anotações:

\section{EXCERTO 2}

Dia 30/09/2010, aula de observação da $5^{a}$ série, a profa. trabalhou tipos de frases, conhecemos três tipos interrogativa, exclamativa e declarativa. A frase interrogativa expressa um questionamento, ex: Por que você foi embora?

Aluno1: qualquer pergunta é uma frase interrogativa e mais o ponto de interrogação no final? 
Profa.: Sim, essa é uma boa maneira de identificá-la.

A exclamativa expressa emoções: admiração, surpresa, espanto, alegria etc. sempre acompanhada de ponto de exclamação: ex.: que livro legal!

Profa.: que sentimento está expresso nessa frase?

Aluno1: Para mim nenhum não gosto de livro.

Profa: Estou falando em relação ao tipo de frase.

Aluno1: acho que quem ganhou o livro ficou contente

Profa.: isso mesmo demonstra alegria, por isso, é exclamativa.

A frase declarativa pode ser afirmativa e negativa, ambas terminam com ponto final. Ex.: O gosto pela leitura traz benefícios valiosos para nós. Ex.: Fumar não é saudável.

Aluno2: não deu pra entender nada nestes exemplos.

Profa.: é simples, a frase declarativa é tudo o que falo esteja afirmando ou negando alguma coisa.

Façam os exercícios. Um aluno levou o caderno para correção: Profa.: Ele sabe muito bem identificar as frases, levou em consideração os pontos de $(?$, !,.) no final da frase, que bom! Já é um bom começo para entender este assunto.

No excerto 2 também há um "narrador" praticamente mudo, reduzido à marcação dos locutores no início de cada linha; o andamento do relato é dado pela sucessão das falas citadas sem intervenção de uma instância narrativa. O recorte do dado, no entanto, é mais pertinente do que no excerto 1 , pois o estagiário cede a palavra para mostrar as trocas entre professora e alunos a respeito de um conteúdo da disciplina. A escuta é mantida de forma mais consistente, permitindo o registro de vários turnos em sequência e fornecendo informações sobre a metodologia de ensino da professora e os conceitos construídos no diálogo entre ela e os alunos (nos cinco turnos subsequentes à pergunta "que sentimento está expresso nessa frase", por exemplo, pode-se discutir se a categorização dos tipos de frase obedece a um critério pragmático, referencial ou formal). Neste caso, portanto, o estilo "linear" leva ao registro de dados suficientemente detalhados para ensejar análises posteriores da aula.

B. Por outro lado, encontramos relatos em que os estagiários adotam um estilo condensado de registro, próximo ao que Bakhtin nomeia de estilo pictórico. Esses relatos dão preferência ao discurso indireto e 
podem produzir algumas passagens em "discurso indireto livre" - isto é, trechos em que, normalmente ao citar falas longas, o conteúdo do discurso citado passa a ser introduzido sem marcas explícitas, mesclando-se ou mesmo confundindo-se com o discurso citante. Numa situação extrema, mas comum, o próprio ato de fala aparece de forma implícita, sendo substituído por um nome ou expressão nominal que o designa. Nesses casos não se pode falar em "discurso reportado" propriamente dito e, em geral, há uma perda de informação importante, pois o conteúdo do enunciado tende a não ser registrado ou surgir, de forma compacta, como um adjunto'.

O "estilo pictórico" se caracteriza, para Bakhtin, pela atenuação ou apagamento das fronteiras entre o discurso citante e o discurso citado. Em suas palavras, "a língua elabora meios mais sutis e mais versáteis para permitir ao autor infiltrar suas réplicas e seus comentários no discurso de outrem" (p. 150). Em contraposição ao "estilo linear", somos levados a pensar em um registro mais reativo, em que o enunciado citado é desde o início retratado com nuances apreciativas; as palavras alheias não são percebidas "em si mesmas", como objeto a ser transcrito, mas chegam à consciência já inseridas no quadro de uma resposta do sujeito a elas. Esse estilo nos traria relatos propensos à avaliação das experiências, à circunscrição de problemas e ao questionamento dos dados recolhidos. Para Bakhtin, no estilo pictórico, "o próprio discurso [narrativo] é bem mais individualizado" (p. 150), em contraste com o estilo linear, no qual, "quanto mais dogmática for a palavra, menos a apreensão apreciativa admitirá a passagem do verdadeiro ao falso, do bem ao mal, e mais impessoais serão as formas de transmissão do discurso de outrem" (p. 149). O excerto a seguir é um exemplo desse estilo de relato.

\section{EXCERTO 3}

Nossos comentários sobre o texto giravam em torno da identificação do conflito, da distinção da voz do narrador, do reconhecimento da escrita dentro da escrita, recurso conhecido como metalinguagem, da qual eles nunca ouviram falar e tão

9 À guisa de exemplo: em vez de uma frase contendo discurso indireto como "o professor perguntou se...", tem-se frases como "o professor fez uma pergunta sobre...", ou simplesmente "o professor fez uma pergunta". 
cedo ouviriam, pois a professora nos informou que não se trabalha mais teoria da comunicação nas escolas, conhecimento este restrito apenas aos especialistas do estudo da linguagem. $O$ foco agora era outro: abordar os textos em seus contextos de uso (será que foi isso que ela disse mesmo? Não lembro).

Comparado com os excertos anteriores, nesse trecho as palavras da professora e dos alunos aparecem de forma menos destacada mas, em compensação, tem-se uma percepção mais clara das posições do estagiário. A sala de aula é, de fato, escutada a partir do modo como ela ressoa na consciência desse "narrador" - inclusive com suas dúvidas em relação ao que foi ou não foi dito. $\mathrm{O}$ estagiário interpela de forma mais direta seu leitor e, por conta disso, também se expõe mais - sente-se falta de maior clareza, por exemplo, com relação ao conceito de "metalinguagem" que está sendo evocado e sua relação com a "teoria da comunicação". Ele também parece encontrar alguma dificuldade no manejo das vozes que compõem seu discurso, de modo que não fica completamente claro qual foi o teor da aula que está sendo discutida, nem qual é o tom assumido pelo estagiário ao relatá-la - pode-se perguntar, de fato, se o estagiário está ironizando as palavras da professora ou relatando uma fala irônica da própria professora.

Observemos isso de modo mais esquemático. Na condição de "narrador", o estagiário cita suas próprias palavras ("nossos comentários") enquanto "personagem" do discurso e também as palavras da professora. Se usarmos os termos de Ducrot (1987), diremos que se trata de um locutor L que relata as palavras de um locutor $\lambda 1$ - correspondente ao mesmo sujeito empírico de $\mathrm{L}-\mathrm{e}$ de um locutor $\lambda 2$ - correspondente a outro sujeito empírico, a professora. O primeiro trecho em negrito corresponde ao teor dos comentários de $\lambda 1$ - registrados de forma vaga, aparentemente pautando-se na pressuposição de um discurso mais referido do que citado, isto é, na premissa de que o teor do discurso citado (o que é "conflito" na teoria da narrativa etc.) seria de comum conhecimento para locutor e alocutário. É um tanto nebuloso, contudo, em que medida esse trecho consiste em um resumo analítico das palavras de $\lambda 1$ ou em um comentário imediato de L direcionado ao seu leitor.

Seguindo a mesma linha de análise, o primeiro trecho sublinhado é uma passagem em relação à qual, por um efeito de sintaxe, já não 
conseguimos determinar se se trata de uma continuação do discurso indireto de $\lambda 1$ (o próprio estagiário teria explicado o que é metalinguagem e comentado que os alunos dificilmente ouviriam falar nisso), de um comentário de $\mathrm{L}$ a respeito do discurso citado de $\lambda 1$ (o estagiário estaria fazendo esse comentário apenas no texto escrito, direcionando-se ao supervisor enquanto seu leitor), ou ainda, de uma antecipação de parte do conteúdo da fala de $\lambda 2$, a professora (ela é quem teria nomeado o conceito como "metalinguagem" e comentado sobre a exclusão da "teoria da comunicação"). Pode-se observar que a conjunção "pois" pertenceria a locutores diferentes $(\lambda 1, \mathrm{~L}, \lambda 2)$ em cada uma dessas hipóteses.

$O$ segundo trecho em negrito é o registro do teor de uma fala da professora $(\lambda 2)$, desta vez registrado de forma mais fiel, num estilo mais próximo ao linear - mas não se compreende exatamente em que momento esse enunciado teria sido pronunciado, pois ele é introduzido com um valor "retórico" (como o objeto da ironia presente na passagem anterior) e não com um valor "referencial" propriamente dito. Como consequência, também não é possível ter certeza sobre se esse trecho foi dito com ironia pela professora ou se foi dito por ela de forma séria e, a seguir, citado pelo estagiário com ironia. $\mathrm{O}$ último trecho sublinhado - um comentário do locutor $\mathrm{L}$ - não esclarece esse ponto, já que põe em dúvida (no plano do sentido explícito) se o trecho antecedente de fato corresponde às palavras de $\lambda 2$. Não nos parece claro qual o "acento expressivo" desse comentário, mas ele depende da maneira como se interprete a expressividade da passagem anterior, em negrito.

Poderíamos parafrasear todo o excerto 3, adotando um estilo "linear", mais ou menos como - "enquanto explicava como identificar o conflito de uma narrativa etc., a professora comentou que não se trabalha mais com a teoria da comunicação etc.". Parece-nos interessante considerar, em todo caso, que não é dessa forma puramente sequencial que o estagiário percebe a cena (como vemos, por exemplo, em 2), mas enquanto um intenso diálogo e, sobretudo, por meio de um descentramento da própria consciência, perceptível tanto nos comentários sobre suas falas em sala quanto no "diálogo interior" instalado dentro do último parêntese. Ambos os traços podem estar sinalizando um movimento reflexivo importante, promovido ou ao menos prolongado na atividade de escrita. Por outro lado, temos que reconhecer que a expressão desse "diálogo interior" em forma de texto não foi completamente bem sucedida e talvez exigisse um refinamento do próprio estilo de escrita. Além 
disso, nos vemos impossibilitados de fazer quaisquer considerações sobre a aula efetivamente ministrada pelo estagiário a partir da leitura de seu texto, já que há pouca clareza sobre como ela se desenrolou.

C. Além dos estilos "linear" e "pictórico", Bakhtin menciona um "caso extremo" que poderia chegar a constituir um terceiro estilo de "discurso reportado".

“(...) existe também um outro tipo, em que a dominante do discurso é deslocada para o discurso citado; esse torna-se, por isso, mais forte e mais ativo que o contexto narrativo que o enquadra. Dessa maneira, o discurso citado é que começa a dissolver, por assim dizer, o contexto narrativo. Esse último perde a grande objetividade que lhe é normalmente inerente em relação ao discurso citado; nessas condições, o contexto narrativo começa a ser percebido - e mesmo a reconhecer-se - como subjetivo, como fala de 'outra pessoa'." (p. 151, destaques nossos)

Temos que considerar que Bakhtin está se referindo à situação em que esse efeito é obtido propositalmente por um autor e consiste em um elemento estilístico de seu discurso. Em todo caso, encontramos situações nos relatórios de estágio em que se torna necessário indagar até que ponto é o discurso narrativo citante, e não o discurso citado, que controla a construção do relato, conferindo a ele seus tons expressivos e inserindo nele direcionamentos argumentativos, pontos de vista ou conclusões. $\mathrm{O}$ excerto 3 pode ser analisado dessa forma, mas há casos em que esse efeito é mais evidente - como a seguir:

\section{EXCERTO 4}

Em seguida, a diretora A.K chegou com a professora na porta da sala e ordenou " $D$. pegue os seus pertences e se retire da sala de aula e vamos até a diretoria, pois você pegará suspensão de 15 dias e só aparecerá com os seus pais ou responsáveis". $O$ aluno D. pegou o seu caderno e saiu ameaçando a professora "é a senhora vai ver só deixa eu voltar que a senhora vai dever na minha mão". Confesso que eu fiquei com medo, pois pelo que eu notei, esse aluno possivelmente tem envolvimento com drogas ou 
pessoas de índole duvidosa (...) conclui que a partir de situações desse tipo é que há muitos casos de assassinato de professores.

Neste caso, temos o relato de um episódio de conflito no qual algumas falas são retratadas com vivacidade, em discurso direto, pelo estagiário. Tanto o teor dessas falas quanto a redação conferida a elas, que nos parece bastante "autêntica" enquanto representação plausível de enunciados falados, relegam o discurso narrativo a um segundo plano: são as vozes da diretora, interrompendo a aula para ordenar a saída de um aluno, e do próprio estudante expulso, ameaçando a professora de forma um tanto crítica, que se fazem escutar nessa passagem - e não a voz do narrador. Quando este assume a condução do relato, na segunda parte do fragmento (sublinhada), o peso das falas das "personagens", especialmente a imprecação do aluno D., ainda é tão grande que o narrador permanece à sua sombra, por assim dizer. Todas as conclusões arroladas nessa coda parecem desdobrar-se, essencialmente, a partir do tom impresso pelo diálogo antecedente e não de qualquer evidência concreta coletada pelo estagiário indicando, por exemplo, que o aluno em questão realmente seja usuário de drogas ou pretenda cometer $\mathrm{o}$ assassinato da professora. $\mathrm{O}$ choque entre as vozes dos dois "antagonistas" tinge o texto com as cores necessárias para que a incriminação do estudante expulso se torne plausível sem maiores esclarecimentos.

\section{A relação entre o "plano do autor" e o "plano da personagem"}

O último dado levanta algumas questões que dizem respeito ao jogo de forças entre o discurso que cita e o discurso que é citado. Dentre elas escolhemos três sobre as quais discorremos com mais minúcia.

A. Primeiramente, como o discurso narrativo apreende o discurso reportado. Bakhtin fala em uma vertente "analisadora do conteúdo" e uma "analisadora da expressão"10.

A enunciação de outrem pode ser apreendida como uma tomada de posição com conteúdo semântico preciso por parte do falante, e nesse caso, através da construção indireta, transpõe-se de maneira analítica sua composição objetiva exata (o que disse o falante). (...) Mas pode-se também apreender e transmitir de

10 Embora Bakhtin se refira ao discurso indireto quando propõe essas categorias, parece-nos que não é necessário associar essas vertentes apenas a essa modalidade de discurso. 
forma analítica a enunciação de outrem enquanto expressão que caracteriza não só o objeto do discurso (que é, de fato, menor) mas ainda o próprio falante: sua maneira de falar (individual, ou tipológica, ou ambas); seu estado de espírito, expresso não no conteúdo mas nas formas do discurso (por exemplo, a fala entrecortada, a escolha da ordem das palavras, a entoação expressiva, etc.); sua capacidade ou incapacidade de exprimir-se bem, etc. (Bakhtin, 2015, p. 160)

Nos relatos de estágio que analisamos há um pendor pela reconstituição do conteúdo dos enunciados citados em detrimento da expressão. Encontram-se poucos comentários sobre o modo como as falas foram pronunciadas; elementos como a prosódia, o tom e volume da voz, os acentos expressivos conferidos a certas partes do enunciado, gestos e outros elementos "corporais" da fala raramente são mencionados ou representados de alguma forma. Esses aspectos eventualmente podem ser inferidos, mas não parece haver uma preocupação consciente dos estagiários em registrá-los ou tomá-los como objeto de uma análise específica. Observemos um exemplo:

\section{EXCERTO 5}

(...) antes de receber os trabalhos a professora chamou a atenção da turma, pois alguns alunos foram reclamar na coordenação da escola que a professora estava passando muito trabalho e muito texto apostilado, a professora com ar de tristeza disse o seguinte aos alunos: "eu estou extremamente decepcionada com vocês, pois acabei de ser chamada atenção pela coordenação que disse que vocês foram reclamar das minhas aulas eu sinceramente não sei o que vocês querem eu estou extremamente decepcionada com a postura de vocês" uma aluna retrucou dizendo "professora não são todos os alunos que estão insatisfeitos com a sua aula é a minoria que por sinal nem veio hoje" (...)

Nesta passagem, o adjunto adverbial "com ar de tristeza" fornece uma descrição sucinta do modo como a professora se dirigiu aos alunos, modificando um verbo dicendi de outra forma bastante neutro ("disse"). No caso da fala da aluna, o próprio verbo dicendi ("retrucou") 
sugere uma tonalidade expressiva ou, ao menos, uma atitude específica em relação ao enunciado antecedente. Em ambos os casos, entretanto, é a própria redação das falas que fornece os elementos mais significativos para se determinar o tom e a acentuação emotiva das palavras citadas. Havia algo muito semelhante no excerto $2 \mathrm{e}$, sem dúvida, no excerto 4; também aqui se trata de uma situação de conflito, na qual a voz da professora e de uma aluna são realçadas, trazidas a primeiro plano como "atores" da controvérsia, enquanto o narrador em si parece participar muito pouco, recuando para os bastidores da cena ${ }^{11}$.

Em todo caso, os estagiários podem demonstrar, em passagens como esta, uma sensibilidade para a escuta ou, ao menos, para a composição linguística dos enunciados "falados", que valeria a pena explorar em prol da caracterização das situações escolares. Estaríamos às voltas com um procedimento semelhante ao que Bakhtin (2015) chama de "estilização" ou uma modalidade de "skaz" - procedimentos relacionados à incorporação dos estilos falados na língua literária e à criação de efeitos variados (ironia, polêmica, paródia etc.) por meio da repetição, às vezes sutilmente modulada, das palavras e dos tons do outro. Parece-nos que o manejo mais controlado desse tipo de técnica poderia ajudar o estudante a se posicionar de forma mais reativa frente à palavra do outro, levando-o a um esforço específico de percepção do estilo alheio e a uma apreensão do outro baseada no estabelecimento de contrapontos e não de pontos de identidade ou fusão. No limite, "estilizar" um relato diminuiria as chances de uma aderência direta às palavras escutadas, instaurando entre o ouvido que escuta e os enunciados escutados a distância de um gesto proposital de mimese.

11 É importante observar também que aqui há uma modulação muito particular dos estilos de discurso. O narrador conduz o relato dentro de um estilo predominantemente "pictórico" (observe-se que na primeira frase do excerto uma fala da professora é referida apenas pela expressão "chamou atenção da turma") mas, em um ponto específico, muda de estilo e destaca um conjunto de falas da professora e dos alunos, assumindo momentaneamente um estilo "linear". Em geral, isso acontece quando se trata de relatar situações de conflito - o narrador estaria procurando não se "comprometer" com falas que denotam polêmica. Mas também temos a impressão de que a razão pela qual essas falas são ouvidas com maior ênfase e transcritas à parte, num estilo que pode destoar do restante do texto, é justamente o fato de que foram falas providas de maior entonação expressiva. Temos de nos perguntar em que medida o estagiário está no controle da própria escuta - isto é, em que medida é sua a decisão de dar ênfase a certas passagens, ou em que medida essas ênfases não expressam mais uma espécie de transcrição direta do relevo expressivo próprio dos enunciados citados. 
B. Há outro tipo de situação em que, inversamente ao que acabamos de ver, o modo como as falas são transcritas nos causa certo incômodo porque a estrutura linguística do enunciado não é favorável a um acento expressivo falado ou, simplesmente, não condiz com o que se esperaria de uma troca verbal espontânea.

\section{EXCERTO 6}

No decorrer da aula a turma estava muito agitada e continuava tendo dúvidas a respeito da resolução de algumas questões que eu observei. Por exemplo uma aluna me perguntou quando era que um verbo estava no pretérito perfeito do indicativo. Que justamente era a $9^{\mathrm{a}}$ questão da atividade que tinha o seguinte comando: "Retire os verbos que estão no pretérito do indicativo" do parágrafo 96?" Eu expliquei para a aluna que o tempo do verbo no pretérito pode subdividir-se em imperfeito, perfeito e mais-que-perfeito. No pretérito imperfeito a ação verbal ou o fato está inacabado. Por exemplo: "As filhas dos pescadores ainda brincavam na praça." Já o pretérito perfeito indica que o fato está concluído, acabado no momento em que se fala. Por exemplo: "As crianças já brincaram lá na praça". No pretérito mais- que- perfeito revela um fato passado que já foi concluído, considerando um fato também passado. Por exemplo: "Quando você resolveu sair de casa, eu já saíra"

No excerto 6, pode causar alguma estranheza o modo como o discurso citado de $\lambda 1$ (aqui correspondente, mais uma vez, ao próprio estagiário mencionado como personagem) está imbuído de um tom que seria mais condizente com o narrador (ou locutor L). Não há um jogo dialógico propriamente dito entre o discurso citante e o discurso citado - este se encontra completamente objetificado, à maneira do discurso do herói no romance monofônico. Uma personagem fala, mas suas palavras soam, desde o início, incluídas no plano mais amplo da narração.

Estamos nos referindo ao fato de que toda a passagem em negrito, no excerto 6 , é apresentada como sendo uma explicação fornecida oralmente para uma aluna, em sala de aula, mas a redação dessa passagem nos parece muito mais próxima de uma exposição escrita. Como o estilo em si não é nosso ponto de chegada, essa percepção nos põe a 
voltas com diversas hipóteses a respeito das condições "exteriores" da escrita. Pode ser que se trate de uma questão de redação: o estudante não fala dessa forma, mas reestiliza seus enunciados, adequando sua forma linguística ao que considera apropriado para o registro escrito - com isso, perdendo ou modificando aspectos de sua tonalidade expressiva original. Pode ser, por outro lado, que o estudante não apenas tenha "reestilizado" sua fala, mas tenha efetivamente buscado, depois da aula, uma explicação para a dúvida da aluna e substituído o enunciado falado original por uma citação relativamente direta dessa fonte secundária. Neste caso, não há como saber até que ponto a explicação dada em aula coincide com a que foi encontrada mais tarde, e o pequeno diálogo entre estagiário e aluna se converteria em um volteio retórico direcionado ao supervisor, cuja finalidade não seria mais pôr em pauta uma experiência de ensino, mas demonstrar que se tem domínio de um certo conteúdo ${ }^{12}$.

C. Por último, queremos considerar a possibilidade de que, na escuta da aula, o estagiário desenvolva uma escrita mais próxima do que Bakhtin caracteriza como "polifonia" a partir de sua análise da poética dostoievskiana. Nessa obra, Bakhtin propõe uma categorização tripartite dos tipos de discurso. Haveria o discurso referencial - "concretamente orientado", "que nomeia, comunica, enuncia, representa" (p. 213) -; o discurso objetivado - "orientado para o discurso de um outro" (p. 213), exemplificado pelo "discurso direto dos heróis" -; e haveria, por fim, os discursos duplamente orientados para o referente e para o discurso alheio, também chamados de "bivocais". Todas as formas de estilização, imitação e paródia consistem em discursos bivocais para Bakhtin, de modo que nos excertos 4 e 5 teríamos, ao menos, um embrião de bivocalidade, ou seja, discursos que ao mesmo tempo registram um "conteúdo" e retém algo do modo como esse "conteúdo" se materializou nas palavras de outro.

12 Essa segunda hipótese levanta um problema relacionado às concepções de formação que orientam a escrita dos estudantes (e também as ações dos formadores). Mais importante do que isso, no entanto, é que essa concepção nos fala da possibilidade de interdição da aula como objeto de pesquisa. Não seria possível, dentro desse discurso, produzir conhecimento sobre o ensino (ao menos não pelos meios "científicos" habituais), porque uma série de movimentos retóricos (embutidos nos próprios estilos de escrita favorecidos pelo "gênero") estaria pronta para refratar a apresentação da aula como dado. A análise seria desfavorecida em relação a outros procedimentos. 
Essas modalidades, em todo caso, são consideradas por Bakhtin formas de discurso bivocal "passivo", porque tomam "a palavra indefesa e sem reciprocidade do outro e a reveste[m] da significação que ele, autor, deseja, obrigando-a a servir aos seus novos fins" (Bakhtin, 2015, p. 226). Na paródia, na estilização e na imitação o discurso do outro é levado em conta, mas na condição de discurso encerrado, de palavra anterior e, por isso mesmo, em certa medida ausente. Na modalidade "ativa" do discurso bivocal, ao contrário, a palavra do outro estaria incorporada enquanto presença viva, contemporânea ao discurso primeiro. Bakhtin associa essa forma de discurso, dentre outros, à "autobiografia e confissão polemicamente refletidas". Sentimo-nos tentados a buscar relatos em que se possa identificar esse estilo de discurso, mas não o encontramos ${ }^{13}$ - há ensaios ou passagens que podem sugerir um direcionamento incipiente nesse sentido.

\section{EXCERTO 7}

Em um desses momentos a professora disse que a primeira coisa que tinha que mudar era a ideia que eles tinham de pesquisa, usou como exemplo "as capas de trabalho que não mudam em todas as matérias" - fala própria da professora.

\section{EXCERTO 8}

O texto também fala que o jovem utiliza uma linguagem apenas de confirmação, que este está perdendo a capacidade de formular pensamento e que por isso muitas vezes não completa frases. A professora usou esse terceiro texto para, de certa forma, provar o que é mostrado no texto 2 - provar foi o termo que ela usou.

13 A "confissão" existe enquanto uma forma estilística do discurso sobre o ensino, mas não em uma modalidade "polemicamente refletida" - tratam-se dos discursos em que um professor "confessa" suas práticas supostamente obsoletas e, a seguir, declara sua "submissão à lei", isto é, sua adesão à vertente de maior força política no momento. Há uma bivocalidade nesse discurso, mas ela é do tipo "passivo" - a voz do próprio professor é desdobrada em duas, uma que relata as "velhas convicções" e outra que "as reconhece em falta". A primeira é completamente neutralizada pela segunda. 


\section{EXCERTO 9}

Após isso, ela disse aos alunos que essa sua apresentação do texto e da biografia de La Fontaine deveria ser usada como modelo para o seminário - seminário esse que seria o ponto alto do "projeto".

Os três excertos acima, extraídos de um mesmo relatório, mostram a "dupla orientação" do discurso - ao mesmo tempo em que as palavras da professora são ouvidas e registradas, elas também são descentradas pelos comentários da estagiária, apresentadas com uma nuance parodística. $\mathrm{O}$ discurso citado é ao mesmo tempo fac-símile das palavras do outro e nova enunciação, na qual o tom original é acrescido de uma nota apreciativa. É verdade, contudo, que o relatório não ultrapassa o que se vê nos excertos de 7 a 9 . Não se percebe uma "polêmica velada" entre o discurso da estagiária e o da professora - este é ouvido com cautela, mas não instaura uma verdadeira dúvida na posição de quem o escuta.

Nosso interesse pela possibilidade de um relato que se aproximasse mais de uma "bivocalidade ativa" reside na intuição de que ela pode ser necessária para transcender as condições nas quais a sala de aula é dada ao universitário enquanto objeto de descrição, instaurando uma forma talvez ainda inexistente de escuta da palavra da escola enquanto discurso pleno. Uma pesquisa com potencial inovador necessitaria, segundo nossa intuição, de um recurso aparentemente escasso - a possibilidade de se observar a escola desde o lugar da dúvida e de se falar sobre ela sem o imperativo da certeza, da segurança em si.

[No discurso bivocal ativo] já não há dominação absoluta da ideia do autor sobre a ideia do outro, a fala perde a sua serenidade e conviç̧ão, torna-se inquieta, internamente não solucionada e ambivalente. Semelhante discurso não tem apenas duas vozes, mas também dois acentos; é difícil dar-lhe entonação, pois a entonação viva e estridente o torna demasiado monológico e não pode dar tratamento justo à voz do outro nele presente." (Bakhtin, 2015, p. 227) 
O próprio Bakhtin reconhece que essa forma de discurso não é possível em qualquer época ou sob quaisquer condições - ele seria impossível na poesia e, na prosa, teria florescido no século XIX. Temos que considerar que ele talvez ainda não tenha se elaborado no seio da "escrita testemunhal" em que os relatórios de estágio consistem em nossa atualidade. Mas isso não nos isenta de perguntar em que consistem as práticas de pesquisa com que convivemos se, ao longo das últimas décadas, tendo ido com tanta frequência à escola, elas não elaboraram um estilo de descrição que permita escutar os próprios dados de forma não monológica. O fato de que o "gênero" não disponha dessa modalidade de escuta também não quer dizer que seja individualmente impossível ou vetado chegar a ela, mas apenas que para isso se faz necessário um trabalho de cunho mais autoral.

\section{Considerações finais}

Procuraremos encaminhar as questões que vislumbramos aqui, com relação à formação de professores, em dois pontos.

Primeiro - parece-nos viável discutir o papel do estilo nos processos de pesquisa, e provavelmente é necessário discernir melhor as instâncias em que o estilo pode ser tomado nesse tipo de discussão. Por enquanto, ficamos com a hipótese de uma dialética entre os estilos comuns, dados pela escrita acadêmica enquanto instituição, e os estilos individuais daqueles que se servem dela para elaborar parte de sua experiência vivida. Estudantes tem personae distintas, por assim dizer, e as possibilidades de conhecer os objetos de seu campo não são as mesmas conforme elas se configurem. Há estudantes cujo ethos pende para o sério, o solene, às vezes o estoico; para esses deve ser mais difícil ver com ironia um equívoco ou um quiproquó, o que é o mesmo que dizer: a ironia e seus parentes, enquanto operações retóricas, serão menos úteis a eles como porta de entrada para a análise de determinadas situações. Há estudantes cujo humor é mais saturnal, e estes podem ter no riso, na paródia ou nas formas de "carnavalização" um conjunto de recursos mais produtivo. E assim por diante. Existem, inclusive, diferenças em relação ao modo como os sujeitos se posicionam dialogicamente em relação a si mesmos. Uns parecem buscar como horizonte a construção de um mundo monolítico, dominado por um único ponto de vista que polarize todas as possibilidades de apreciação de um determinado objeto - o que se reflete na forma e no teor de seus textos, mas 
também na maneira como leem, no tom que atribuem aos autores, e no modo como escutam seus semelhantes. Outros se sentem mais confortáveis em meio a vozes desencontradas e escutam com mais facilidade as contradições e as astúcias de quem fala. Uma intervenção ou um comentário do formador que incidam sobre um elemento estilístico (e não semântico ou de "conteúdo") podem afetar não só o estilo do texto do aluno, mas o modo como ele percebe seu objeto e a posição que sustém perante uma ideia. A pesquisa sobre o estilo no discurso acadêmico pode ajudar a esclarecer até que ponto esse tipo de questão é relevante para a qualidade dos resultados obtidos.

Nos relatórios que analisamos, predomina um estilo de escrita sem acentos expressivos claros, em que a representação das palavras do outro se assemelha a uma transcrição. Essa escrita parece fundar-se sobre um ethos "neutro" (o narrador tende a perder relevo) e um certo ideal de "objetividade". Encontramo-la bem desenvolvida em alguns casos, resultando em relatos consistentes, mas predominantemente descritivos (como exemplificado em 2). Há situações em que, dentro desse registro "neutro", o estagiário comenta e opina, mas o faz de forma explícita e paralela aos dados - a voz que opina surge ao lado das demais vozes citadas e não lança sobre elas nenhuma nuance particular. Como resultado, tem-se comentários tópicos, que não chegam a conferir ao conjunto do texto um direcionamento argumentativo claro.

Quando há um tom expressivo mais consistente, o discurso citado é monológico (é o que vimos em 4, 5 e 6). Há tomadas de posição, questionamentos e comentários que podem ser mais ou menos pertinentes conforme o caso. Mas o registro das falas não alcança instaurar um discurso bivocal "ativo", em que professores e alunos, enquanto "personagens" do relato, sejam escutados de forma mais próxima às "consciências plenivalentes e equipolentes" que caracterizam, para Bakhtin, o romance polifônico (chegamos mais perto em 3 e 7-9). Por melhores que sejam as discussões levantadas pelo estagiário, por mais que suas impressões estejam ajustadas aos fatos, os dados surgem enfeixados por um determinado ponto de vista, equacionados no "plano geral do autor". Não nos interessa concordar ou discordar do teor dos relatórios; interessa-nos mostrar que, dentro das possibilidades de estilo disponibilizadas por esse gênero de escrita, certas nuances expressivas são favorecidas, de tal forma que os termos, as frases, os encadeamentos argumentativos, os tons e as ênfases relacionados a elas se apresentam 
mais facilmente a quem escreve. Os acentos que encontramos mais desenvolvidos nos relatórios são a ironia, a reprovação, a queixa, o lamento - pode-se pensar, hipoteticamente, que esses tons compõem um estilo mais institucional do que individual. Seria, então, uma espécie de norma da casa, para quem está na universidade, levar a conversa com a escola em um tom mais blasé.

Segundo ponto - se nossa hipótese porventura estiver correta, é óbvio que só se tem a ganhar com o acréscimo de outros tons e "mindsets" ao repertório dos estilos de escrita institucional. Tê-los e escolher não usá-los é completamente diferente de não dispor de outras palavras para falar da escola. Sobre esse ponto, que não é de fácil solução, temos arriscado ao menos uma proposta concreta: seria necessário que, em sua formação, o estagiário fosse levado a experimentar diferentes formas de escrever sobre a escola, ainda que, a princípio, num registro ficcional, como puro jogo de imaginação. $\mathrm{O}$ professor precisa ter à mão recursos expressivos que permitam pensar e sentir a experiência de outras maneiras que não aquelas já dadas pelo discurso em seu estado presente, de forma que sua experiência individual contribua para a gestação das formas futuras desse discurso e dos discursos que se desdobrarão a partir dele. Seu preparo para a sala de aula tem que colocá-lo em condições de produzir suas próprias formas de apreensão da realidade - o que requer um trabalho sobre a língua do qual boa parte dos estudantes parece estar em falta. Acima de tudo, é preciso que o professor esteja em condições de se defender das ideias e das emoções vestigiais que assombram os lugares-comuns da escrita mediana. Dominar a escrita - ser capaz, por exemplo, de redigir um diálogo eivado de sutilezas, representando os semitons de uma conversa autêntica, as insinuações, os mal-entendidos, as deixas perdidas - tudo isso constitui um acervo de habilidades que não poderia atrapalhar o estudante imbuído de registrar um dado naturalístico.

Nossa passagem pela obra de Bakhtin deixa a impressão de que o texto literário poderia vir ao auxílio neste mérito, fornecendo uma inesperada contribuição para os objetivos das licenciaturas. O próprio Bakhtin comenta, a respeito de Dostoiévski, que um de seus méritos teria sido o de saber escutar o "Grande Diálogo" de sua época. Essa forma de pensar a literatura, a nosso ver, aproxima o escritor do pesquisador embrenhado na escola: também a escrita literária (ao menos algumas formas dela) seria, na raiz, um exercício de escuta - dos estilos de fala 
das ruas, sempre renovados e instáveis; das relações sociais em gestação e mudança constantes; dos impasses e crises que vão sutilmente se anunciando na vida corriqueira, inclusive no microcosmo das salas de aula, antes de eclodirem e ganharem uma forma dizível, um discurso que permita explicitá-los. A literatura seria, para o professor, um dos meios para a formação dessa escuta.

\section{Referências}

Bakhtin, M. (2004). Marxismo e filosofia da linguagem. Tradução de Michel Lahud e Yara Frateschi Vieira. 11a. ed. São Paulo: Hucitec.

Bakhtin, Mikhail. (2010). Os gêneros do discurso. In: Estética da criação verbal. Tradução do russo de Paulo Bezerra. (p. 261306). 5a edição. São Paulo: WMF Martins Fontes.

Bakhtin, M. (2015). Problemas da poética de Dostoiévski. Tradução de Paulo Bezerra. 5a edição. Rio de Janeiro: Forense.

Ducrot, O. (1987). O dizer e o dito. Revisão técnica da tradução de Eduardo Guimarães. Campinas: Pontes.

Geraldi, J. W. (2010). A aula como acontecimento. In: A aula como acontecimento. (p. 81-93). São Carlos: João \& Pedro Editores.

Riolfi, C. R. (2011). Lições da coragem: o inferno da escrita. In: Riolfi, C. R. e Barzotto, V. H. (Orgs.). O inferno da escrita. Produção escrita e psicanálise. (p. 11-31). Campinas: Mercado de Letras. 
